is both the tendency of private security actors to cross into the war-fighting environment and that of states (in Africa) to use private security potential for matters other than the national interest. Simultaneously non-state actors should be considered part of the problem if they use private security actors as a Trojan horse to cross into the war-fighting arena or undermine legitimate state interests. These are perhaps the only two matters that need to be reconsidered.

The publication contains interesting diagrams on the structure of private security firms. They reflect the scope, diversity as well as the independence of private security firms to play their role and adjust to the needs of the client - whether a state or a non-state actor such as MNC's. It creates the impression of an industry gearing itself towards an environment where it is to operate amongst equals and make use of business opportunities that might arise. Its corporate structure therefore should reflect the flexibility and adaptability to respond to both the current African-type needs as well as the more sophisticated customer. Lt Col François Vrey, Department of Military Strategy, University of Stellenbosch (SA
Military Academy)

\author{
MODERN STRATEGY \\ Colin Gray \\ Oxford University Press: Oxford, 1999. \\ 412pp \\ Preface \\ References and index
}

This recent publication by Colin Gray is perhaps the most modern source of information for understanding the realm of strategy, the current as well as the future strategic environment and its complexities. The publication represents three decades of intellectual property of one of the world's leading theorists on strategic theory - a phenomenon understood by very few decision makers, but in demand of their close and daily attention whilst grappling with its complexities in a demanding world. It is a publication in the words of the author '....[b]ut this work is neither a strategic history of the $20^{\text {th }}$ century nor a history of strategy in the twentieth century - rather Modern Strategy is principally about characteristically modern expressions of the ageless phenomena of strategy' The publication thus represents an effort to clarify and give enduring substance to the field of strategy as it increasingly becomes engulfed in rising layers of complexity.

Gray leads the reader down a logical pathway of strategic theory, its history and the future. Six questions are posed to shape the structure and arguments of the book. [1] How do the theory and practise of strategy interact? [2] What has the growing complexity of defence preparation and war meant for strategy? [3] Why is strategy so difficult? [4] If strategy and war has so many dimensions, is it probable that superiority in one/several such dimensions can deliver victory? [5] What has changed for strategy in the $20^{\text {th }}$ century and what has not? [6] What does the strategic experience of the $20^{\text {th }}$ century tell us about what is probably to come in the $21^{\text {st }}$ century? The dimensions of strategy are presented and in particular the important role 
of strategic culture occupies a central position in the publication. Using this departure, the author uses the consequent chapters to address the complexities of strategy - to be understood as the use of coercion (or the threat thereof) in pursuit of policy objectives - by probing the six fundamental questions posed at the beginning of this paragraph. The arguments move from an abstract theoretical perspective towards the more substantive dimensions of strategies formulated over time and the challenges of the nuclear strategy and conflicts other than war.

In chapter one the dimensions of strategy is the focus. The definitional difficulties and options, as well as the many dimensions to be understood in formulating sound strategy receive attention. Although the definitional issues are somewhat fuzzy, the dimensions are substantive and clearly defined. People and politics, preparation for war and war proper are used as organising phenomena and the chapter is concluded with why strategy matters in the planning and conduct of war. Chapter two, Strategy, Politics and Ethics, argues the traditional link between politics and strategy. It also outlines the effect of ethics in effecting the desired behaviour and as such being an unpredictable variable in the politics-strategy equation. The unpredictability of humanity versus the normative or expected matters of strategy and its outcomes receives much attention. The real incompatibility between politics and war, the participating politicians and soldiers and their divergent thinking and cultures are used to illustrate the depth and structure of difficulties experienced in the formulation of strategy proper. Behaviour and changing preferences are here pointed out in terms of their influence upon the efforts to formulate strategy in more enduring terms. 'The Strategist's Toolkit', chapter 3, is about the utility of Clausewitz and in particular the contemporary and continuous value of his views. As a foundation of strategic theory, Clausewitz's contributions and its future utility are put forward and held as the most enduring and authoritative foundation for understanding the phenomena of war and strategy. According to the author the experiences and theories of Clausewitz remains the dominant guide for strategy - both its theory as well as its practicalities. The author however acknowledges the shortcomings of Clausewitz in terms of the current strategic environment. This chapter is followed by one where Gray points out the limitations or poverty of modern strategic thinking. However, he further argues the reasons for this poverty and how we should understand it and even more important, how to cope with it. This is illustrated by Gray debating the partial post-Clausewitzian theories that were developed and the absence of a dominant and general theory of strategy to deal with the complexities of war at the level of Clausewitz's general and enduring utility. Partial theories vs a general theory is further debated in terms of the utility of the post-Clausewitzian theories and their limited scope vs the Clausewitzian theory as the dominant and perhaps most mature and general theory decision-makers have available. Chapter five addresses the issue of strategic culture and the author manages to link the traditional fuzziness of culture to strategy and outline its importance, if not central role, in decisions, actions and thinking. The scarceness of literature on this topic is addressed as well as its prominence in the actions of communities - reflecting some input or outcome of culture in the behaviour patterns and ideas that culture and decisions can only be separated with great difficulty, if possible at all. The utility of this chapter is that it concretises two traditionally difficult concepts, strategy and culture, their complex interactions and crucial outcomes to foster an understanding of its position, role and operating dynamics. This is a typical effort at integrating theory and practice in that strategic theory becomes subject to the unpredictability of culture and its eventual feedback effect upon strategies decided upon and executed. No decision-maker 
http://scientiamilitaria.journals.ac.za

concerned with the use of coercion in the pursuit of policy objectives should proceed without reading and constantly reconsidering this chapter on strategic culture.

From chapter six 'Windows on War' onwards the phenomenon of war is addressed more closely. This chapter outlines general war experiences from a historic approach. The necessity and utility of history in the development of strategic theory and its understanding are central themes in the chapter. History contains various approaches or windows on how to view or approach strategic theory from history. Although the author admitted that this publication is not about the history of strategy, this chapter contributes to the theme in that it presents the ways in which war could be studied and the instruments to be used as tools to organise such studies. It does not elaborate on war, it rather assists understanding of the phenomenon. Chapter seven, in contrast to the historic overtones of the previous chapter, pursues the more contemporary experiences and its interpretations in organising particular formats of war. Dialectics and complementarities of strategic experiences form the central arguments of the chapter. The author presents a framework of the developments that acted as building blocks for contemporary strategic theory. These are presented within two dimensions. One, the dominant ideas of offence vs defence and attrition vs manoeuvre are augmented by considering [1] the irregular succession of major wars, [2] industrial revolutions, [3] the rise and fall of a total approach to war, [4] the legitimacy of force, [5] the military effectiveness of conventional conflict and [6] revolutions in military affairs. These are considered primary manifestations sustaining and or directing strategic thinking during much of the twentieth century.

Chapters eight and nine are directed towards the evolving forms of strategy as it finds manifestation in air-, land- and maritime power with the additional consideration of the rising importance of space power and that of cyberspace. Chapter eight deals with terrestrial action, land and maritime, warfare, chapter nine with air- and space warfare as well as the cyber environment. Although its historical side receives attention, it is primarily the utility and detractions of each dimension and its importance to the decision-maker, that receives primary attention in these two chapters. By deepening the approach to a comparison of the strengths and vulnerabilities of each, as well as its operational role, the author unlocks the very essence that decision-makers should be interested in. Existing theory is taken to task and interpreted in terms of its further utility, combined potential or lack of contribution to the strategic debate. The origins as well as the future utility and widening of these horizons are made visible to those in need of acquainting themselves with strategic issues, but not having the advantage of extended exposure to these matters. For those inclined to elevate one dimension to some strategic superiority vis-à-vis the others, these two chapters perhaps represent a catalyst to temper their selfish or even narrow views of matters demanding multiple inputs and solutions. It is however the forward-looking issues of space- and cyber power that strikes for it is here perhaps placed into its correct context vis-à-vis the traditionally dominant spheres of air, land and sea. This chapter not only presents the difficulties and opportunities of these environments, it also contributes to their integration or jointness as well as their futures.

Chapter ten links strategy to the difficult phenomenon of small wars and other non-traditional conflicts. Being a historic, a contemporary and future type of warfare, it needs to be properly understood. The value of this chapter is its linkage of the difficulty of strategy to events that are perhaps viewed as not being amenable to the traditional strategic dictum of ends, ways and means. The difficulty to interface 
traditional strategic thinking (as might be understood from the preceding chapters) with the non-traditional environment receives particular attention. The error of deeming these two dimensions irreconcilable is pointed out before the author continues to elaborate upon how strategic theory is to be viewed in order iv deal with these non-traditional matters. Particularly how the regular forces in the strategic environment adapted to the irregular strategic challenge, as well as its exploitation in terms of political outcomes, are addressed. The author is of the opinion that a possible gap exists between understanding the use of military forces (regular and irregular) for attaining political outcomes when the realm moves into the unconventional or irregular dimension of warfare.

Chapter eleven is directed towards the difficulties of nuclear strategy and its possible consequences. The chapter is primarily retrospective in outlining the difficulties, but argues that the nuclear strategies of the Cold War period were in actual fact successful, though not spectacular. Working in an unclear and unpredictable strategic environment, nuclear strategies were not well ordered and crystal clear phenomena, but in retrospect were functional in terms of what it had to prevent. In chapter twelve the author turns to the matter of nuclear weapons and strategic history to indicate that the nuclear era is to be understood from a historic perspective on strategic weapons that had to effect a particular outcome - a period where they were present and ready to be used. The current and second nuclear age, according to the author, should be understood and managed in terms of the knowledge built up during the preceding years or even decades. By addressing both the hard matters of nuclear weapons as instruments and the more fuzzy issues of world politics where they are to be used, the author assists in creating a pathway towards the $21^{\text {st }}$ century nuclear environment.

Chapter 13 contains some form of synthesis of the matters outlined to underpin the scope or rationale for the publication. The most prominent conclusions on the endeavour of modern strategy are outlined as follows. Strategic theory is a necessary constructing mechanism, but does not contain ultimate and packaged answers to difficult strategic problems. The answers evolve from strategic theory according to needs. The second question on continuing complexity and advances within strategy is answered in terms of one matter or dimension not being a major disturbance to the system or strategic matters. Strategy is the result of many interdependent matters and their functioning. The resulting quality of strategy is not to be understood as the outcome of only one matter, but rather as how many of the critical factors could be harnessed to optimise a certain strategy to be decided upon. As for question three, the author outlines that it is not possible to suddenly overcome the difficulty of strategy. Parallel complexities in the strategic environment seem to continuously cloud the advances made by other developments with matters remaining complex. Strategy, as for the fourth question, remains a matter to be approached holistically. Currently interdependencies are greater rather than smaller. Accordingly it is more difficult to effect strategic outcomes by merely relying on one dimension only. Complex relations abound and the domain of strategy remains important as opposed to elevating one dimension as the ultimate solution. On the fifth question of strategic change in the $20^{\text {th }}$ century the author makes use of Clausewitz and human nature to address the matter. In these two matters, the author finds the rationale to present the continuance of strategy and how to think about strategy in the $20^{\text {th }}$ century. Clausewitz and human nature are the two explaining theories. Clausewitz could obviously not cater for all changes or preferences of human nature and its 
idiosyncrasies. As for the future Gray takes the reader down a pathway where war is not to disappear from the agenda of actors. Similar problems are to be expected into the $21^{\text {st }}$ century. The actors may change, the instruments may be more refined, but strategic history is to repeat itself, strategic theory is to be utilised to address these problems and strategic ends, ways and means are to remain in the deadly game of strategy.

The publication perhaps presupposes some prior knowledge of the field of strategy, but then one has to consider that this remains a matter primarily for those at the senior political or military levels. As a reader, it is preferable that the publication is read a whole and not fragmented for its value is vested in the sum of its introduction, chapters and conclusions. It is quite a weighty publication of 412 pages (references included) with no explaining figures, diagrams or maps. It contains a complete and clear system of references and an index that could be of much value to the serious soldier-scholar.

This publication is a must for senior defence decision-makers and those officers finding themselves at the strategic and joint levels of operations. It is a blueprint to understand the difficulties of strategy, but simultaneously contains pathways towards understanding the phenomenon in itself. It allows for instant reference on the matters of strategy, although one should read and re-read this publication to properly understand its contribution to the modern strategic environment. On the one hand it pursues the meaning of strategy for decision-makers, on the other it promotes understanding for the soldier-scholar on issues being of primary and immediate importance to him for successfully pursuing a professional military career. It contributes to understanding the difficulty of strategy as a phenomenon for soldiers and politicians in their respective fields. Modern Strategy is a definite reader for staff course students in the South African National Defence Force and those involved in Strategic Studies, the use of the military instrument and coercion at the post-graduate level. Lt Col François Vrey, Department of Military Strategy, University of Stellenbosch (SA
Military Academy)

\section{BLACK HAWK DOWN: A STORY OF MODERN WARFARE \\ Mark Bowden}

First published in the United States of America by Grove/Atlantic, Inc: 1999

Penguin Books published edition, with a new afterword, reprinted: 2000

392 pages

maps, photos

ISBN 0140288503

Robert D. Kaplan in his illuminating article "The Coming Anarchy", published in the Atlantic Monthly of February 1994, emphasises the fact that "Africa may be marginal in terms of conventional late-twentieth-century conceptions of strategy, but in an age of cultural and racial clash, when national defense is increasingly local, Africa's distress will exert a destabilizing influence on the United States". This point was clearly illustrated during 1993 in a battle between American 